\title{
El debate sobre la construción del orden democrático y sus condiciones
}

\author{
The debate on the construction of democratic order and its conditions
}

\section{Alfredo Ramos Jiménez}

\section{Resumen}

Una de las cuestiones más relevantes en el debate recientemente abierto sobre la experiencia latinoamericana de la democratización comienza por la necesaria reflexión y análisis de la relación conflictiva entre Estado, sociedad política y sociedad civil en los diversos contextos. De modo tal que la tesis que aquí expongo, en un plano general, sobre la construcción del orden democrático en nuestros países, presupone la primacía de la sociedad política (formas de acción colectiva que se expresan en los diversos partidos y sistemas de partidos) en todo esfuerzo social orientado hacia la democratización de la sociedad en su conjunto. Esta tesis va al encuentro de las simplificaciones populistas que, en buen número de países, han puesto en peligro los avances de la democratización en marcha. Una genuina gobernanza democrática debe asumir el reto de la discusión informada y del debate abierto a las diversas tesis e hipótesis de trabajo sobre el presente y futuro de la democracia en nuestros países.

\section{Palabras clave}

Democratización; Orden Democrático; Sociedad Política; Gobernanza Democrática; Populismo.

\begin{abstract}
One of the most important questions in the recently opened debate on the Latin American experience of democratization begins with the necessary reflection and analysis of the conflictive relationship between the State, political society and civil society in the various contexts. So the thesis that I present here, on a general level, on the construction of democratic order in our countries, presupposes the primacy of political society (forms of collective action expressed in the various parties and party systems) in all social efforts aimed at the democratization of society as a whole. This thesis is confronted with the populist simplifications that, in a number of countries, have jeopardized the progress of democratization in progress. Genuine democratic governance must take up the challenge of informed discussion and open debate on the various theses and working hypotheses on the present and future of democracy in our countries.
\end{abstract}

\section{Keywords}

Democratization; Democratic Order; Political Society; Democratic Governance; Populism. 


\section{Introducción 1}

En la amplia literatura sobre la democratización, América Latina ocupa un lugar de privilegio: las especificidades de las diversas transiciones posautoritarias así como las experiencias nacionales, que se traducen en avances y retrocesos, están en el origen de aproximaciones que lejos de coincidir alimentan el necesario debate sobre lo que Seymour M. Lipset, en un muy conocido texto, asumió como las condiciones del orden democrático (1988). En tal sentido, las contribuciones teóricas y empíricas no se han hecho esperar, desde el momento en que las discusiones se han ido apoyando en los resultados de investigaciones relevantes sobre el presente y futuro de la democracia en todos y cada uno de los países latinoamericanos (HAGOPIAN y MAINWARING, 2005; MAINWARING, BEJARANO y PIZARRO, 2008; WHITEHEAD, 2011; LEVINE y MOLINA, 2011; MORLINO, 2015).

En la medida en que los proyectos de construcción del orden democrático en nuestros países, en los años recientes, se han visto profundamente afectados por la presión de poderosos grupos de interés - políticos, económicos y hasta mafiosos -, por una parte, y por la presencia recurrente de manipulaciones populistas de unos cuantos gobiernos, que se revelaron duraderos, por otra, resulta imperativo detenerse en el estudio de las principales hipótesis y categorías de análisis utilizadas en la promoción de un debate que hoy en día resulta ineludible.

Me propongo en estas notas, entrar en la discusión sobre las posibilidades de la democracia en nuestros países a fin de intervenir en el debate abierto, teórico y político, sobre la construcción de lo que, en palabras de Norbert Lechner, representa ante todo la construcción del "orden deseado" (LECHNER, 2013). Con este objetivo, es preciso abordar, en primer análisis, los problemas de la democratización en su dimensión institucional. En este intento, me apoyaré sustancialmente en el tratamiento de las diversas y aisladas propuestas que, de uno a otro autor y desde hace cierto tiempo, han venido insistiendo en la necesidad de volver nuestra mirada hacia el funcionamiento del aparato del Estado democrático ${ }^{2}$.

\footnotetext{
${ }^{1}$ Estas notas forman parte introductoria de una investigación más amplia sobre la vinculación entre Democratización y Desarrollo en la experiencia latinoamericana reciente.

${ }^{2}$ En este propósito, me han sido muy útiles y estimulantes los planteos y advertencias de Ezra Suleiman sobre lo que él describe como el proceso de "desmantelamiento del Estado democrático" (SULEIMAN, 2005). La vinculación entre estabilidad de la democracia con determinados arreglos institucionales se apoya en los sugerentes planteos de Adam Przeworski (2003, p. 12-17; 2010, p. 3353).
} 


\section{El orden democrático en cuestión}

En la medida en que la reflexión y estudio sobre la relación de fuerzas, en la base del Estado democrático, requiere hoy en día un renovado esfuerzo de imaginación sociológica, comparto el convencimiento de que la investigación sociológica y política debe asumir, hoy más que nunca, el compromiso explícito y efectivo con la defensa y preservación del orden democrático. Como lo observó John Keane hace cierto tiempo, la democracia siempre ha sido objeto de amenazas provenientes de diversos sectores antidemocráticos, pero "la falta de imaginación figura como uno de los peligros más invisibles y alarmantes" (KEANE, 1992, p. 12). Y John Dunn para advertirnos en forma vehemente sobre el hecho de que, si bien es cierto que "necesitamos una teoría sobre la forma en que podamos ejercer el control menos malo posible de los gobiernos de los Estados modernos", no debemos olvidar que "hoy en día, en política, democracia es el nombre de lo que no podemos tener, y sin embargo no podemos dejar de querer" (DUNN, 1996, p. 44).

A la cuestión de saber si ¿puede la democracia ser cualquier cosa? Giovanni Sartori respondió a tiempo y en forma provocativa: "Lo que la democracia sea no puede separarse de lo que debiera ser (...) La democracia resulta de, y es conformada por, las interacciones entre sus ideales y su realidad, el empuje del deber y la resistencia del es. Una democracia existe mientras sus ideales y valores la crean"(SARTORI, 1988, p. 26-27. El subrayado es del autor). Por su parte, Robert A. Dahl puso énfasis en el hecho de que:

Hasta hace tan solo un par de siglos -diez generaciones, digamos-, la historia de auténticos ejemplos de democracia era muy breve. La democracia fue más un objeto de debate filosófico que un sistema político real que pudiera ser adoptado y practicado por la gente. E incluso en los extraños casos en que existió una "democracia" o una "república", la mayoría de los adultos no estaban autorizados a participar en la vida política" (DAHL, 2012, p. 3. El subrayado es mío).

Estas dos observaciones representan todo un reto para el pensamiento político de nuestros días. En esta perspectiva y unas cuantas décadas antes, en la conclusión de su libro, tan normativo como pionero, Joseph Schumpeter se detuvo en la determinación del conjunto de "condiciones de éxito del método democrático", condiciones de estabilidad requeridas para el mantenimiento de todo orden democrático. Para Schumpeter, tales condiciones se pueden concentrar en tres 
principales: En primer lugar, la presencia de una clase política formada por individuos con "aptitud y carácter moral adecuados". En segundo lugar, la existencia de una burocracia capacitada que goce de buena salud y buena reputación, apoyada en una sólida tradición, dotada de un fuerte sentido del deber y de un sprit de corps no menos fuerte para desarrollar y mantener sus propios principios. Y, en tercer lugar, la promoción de una "autodisciplina democrática" en la ciudadanía, acompañada de un nivel intelectual y moral lo suficientemente elevado para estar en capacidad de resistir "contra los ofrecimientos de los fulleros o farsantes o de otros hombres que, sin ser ni una cosa ni otra, se conducirán de la misma manera que ambos" (SHUMPETER, 1983 e 1942; GREPPI, 2012) ${ }^{3}$.

En esta perspectiva, la construcción del orden democrático hoy en día presupone, además de estas condiciones, la presencia de actores sociales comprometidos con la "buena gobernanza", con la vigencia de un constitucionalismo democrático con capacidad para asegurar gobiernos legítimos y eficientes. Y ello, debido al hecho de que los gobiernos de nuestros países, aquellos que asumieron los riesgos e incertidumbre de los procesos de transición, desembocaron por lo general en el establecimiento de gobiernos tan ineficientes y defectuosos, provocando con ello situaciones de desencanto extendido entre los ciudadanos, de "fatiga cívica", etapa primera en el desarrollo creciente de una antipolítica cargada de amenazas y peligros para la frágil e incipiente institucionalidad democrática ${ }^{4}$.

\footnotetext{
${ }^{3}$ En un apartado de su conocido libro, dedicado a los políticos "fulleros y farsantes", José Nun observa el hecho histórico de que "en América Latina (a) entre los funcionarios y los contribuyentes prevalecieron con demasiada frecuencia los pícaros; (b) la mayoría de los beneficiarios de los estratos medios y altos tendieron a ser igualmente pícaros mientras que a todos los demás les correspondió el papel de subordinados y (c) este cuadro no se modificó sino que se agravó de manera considerable desde la década del ochenta, haciendo cada vez menos verosímiles las invocaciones a la justicia social que realizan los políticos en campańa” (NUN, 2000, p. 139-140). Sobre la tesis schumpeteriana aplicada al contexto latinoamericano de la democratización, (MUNCK, 2007; MAZZUCA, 2007).

${ }^{4} \mathrm{La}$ popular consigna antipolítica "que se vayan todos", esgrimida por primera vez en las movilizaciones argentinas anti-gubernamentales de la primera década del siglo XXI, que luego fuera adoptada por los grandes movimientos de protesta en el resto de América Latina, fue desde el comienzo una consigna netamente anti-sistema, no sólo contra los políticos y los partidos, sino contra "todas las élites", revelando a las claras su vocación autoritaria con un innegable contenido antidemocrático. Los líderes populistas de todas las tendencias aportaron a los movimientos de protesta anti-sistema los mecanismos de justificación o legitimación para sus incursiones políticas. Un estudio pionero sobre los orígenes de la antipolítica en América Latina se encuentra en Mayorga (1995). Una sólida introducción a la cuestión de la antipolítica en Crick (2001 [1962]). Sobre la erosión de la
} 
Habrá quien piense que las cosas comenzaron mal desde el momento en que los clientes del tradicional poder oligárquico encontraron en nuestras sociedades obstáculos insalvables y grandes dificultades para convertirse en ciudadanos en el nuevo sistema de poder. De aquí que mi argumento encuentre sentido en la necesidad de preservar el orden democrático a partir del aparato institucional del Estado democrático. Por ello, mi perspectiva no coincide con las propuestas que en el pasado reciente asignaron la prioridad a las tareas de movilización y fortalecimiento de la "sociedad civil" en la transición de las neodemocracias latinoamericanas de las dos últimas décadas del siglo XX, tareas que debían acompañar - no preceder - a las correspondientes de una sólida sociedad política, como la premisa básica de todo esfuerzo colectivo de construcción de un genuino orden democrático.

Conviene por consiguiente detenerse en la observación sobre el presente y futuro de ese orden democrático, particularmente en las especificidades locales de su dimensión institucional, como la instancia en la que se desenvuelve la democracia como proyecto de orden político. En este sentido, cuestiones tales como las de saber “quién gobierna?” y “¿cómo se gobierna?” resultan cruciales para el diagnóstico y prescripción sobre aquellas realidades sociales y políticas que se presentan arropadas bajo el prestigio difícilmente alcanzado por el ideal democrático que, en nuestro tiempo, aparentemente hasta nuevo aviso, ha resistido a las amenazas de alternativas autoritarias desafiantes. Y si bien es cierto que tales desafíos y el establecimiento de las fronteras de la democratización representaron una constante en la agenda teórica de los investigadores y en la práctica política de los principales actores en las décadas recientes, los esfuerzos aislados de unos y otros se revelaron a la larga insuficientes para predecir, si no evitar, las críticas situaciones que hemos vivido y estamos viviendo, caracterizadas en su mayor parte por una grave, a veces profunda, inestabilidad institucional ${ }^{5}$.

Ahora bien, en los años recientes la cuestión parece haberse complicado en los espacios específicos de la investigación comparativa. Y ello se ha debido en gran medida a la debilidad de los instrumentos teóricos utilizados, en las pasadas décadas,

confianza en las instituciones de la democracia (NEWTON y NORRIS, 2000). También Mulgan (1994).

5 Véase la reflexión sobre "los vínculos de la democracia" en Bobbio (1986, p. 51-64). También Hermet (1989 y 2012); Diamond y Platner (1996); Vanden y Prevost (2002); PNUD (2004); Couffignal (2007); Smith (2009); Rouquiê (2010); Rivas Leone (2010); Hellinger (2011); Morlino (2012). 
para medir y explicar los avances y retrocesos de los procesos de democratización en los diversos países. Porque el énfasis recurrente que encontramos en los estudios sobre el funcionamiento de las "democracias electorales", dentro del contexto de todos y cada uno de los países latinoamericanos, pasó por encima de cuestiones cruciales relacionadas con los evidentes déficits de legitimidad, en unos casos, y con la búsqueda colectiva de una elusiva gobernanza democrática, en otros. Cuestiones que con frecuencia fueron identificadas en el origen de un extendido desencanto con la "democracia realmente existente", por una parte y, last but not least, en la base del crecimiento espontáneo de la antipolítica, entendida ésta como el mecanismo populista de rechazo y condena de la práctica democrática ${ }^{6}$.

En su referencia al malestar que se experimenta tanto en las "mejores" como en las "peores" democracias, Andrea Greppi describió la situación en estos términos: "Malestar, desencanto, fatiga: son demasiadas las voces que apuntan en esta dirección como para pensar que entre ellas no haya más que el reflejo de la crónica melancolía de intelectuales ociosos o el irresponsable instinto contestatario de unos pocos ciudadanos alborotados" (GREPPI, 2012, p. 23) 7 .

Sin embargo, el problema no radica en la presencia de agudas críticas hacia el "orden que tenemos" o de manifestaciones, violentas o pacíficas, de los desencantados e indignados en las sociedades occidentales. Más bien, la cuestión se remonta a causas más remotas en el tiempo y tiende a complicarse cuando el abordaje es asumido como un asunto puntual o excepcional, un asunto más bien relacionado con los ciclos o temporalidades del proceso de construcción del orden democrático: a los períodos previos de exaltación o fascinación por la democracia suceden otros caracterizados por la desilusión y la perplejidad, lo que, a la larga, ha provocado graves tensiones sociales $^{8}$. En el análisis de esta situación, que no ha cambiado mucho en los años

\footnotetext{
${ }^{6}$ Un estudio crítico de los diversos "modelos" de la democratización en la época reciente se encuentra en Geddes (2009). También Anderson (1999). Un esfuerzo teórico de síntesis en Mahoney (2003).

7 "La nueva generación - observó Tony Judt - siente una honda preocupación por el mundo que va a heredar. Pero esos temores van acompañados de una sensación general de frustración: nosotros sabemos que algo está mal y hay muchas cosas que no nos gustan. Pero ¿̇en qué podemos creer? ¿Qué debemos hacer?. Esta actitud es el irónico reverso de la de una era anterior. En la época del dogma radical, los jóvenes estaban lejos de sentir incertidumbre. El tono característico de los años sesenta era el de una confianza presuntuosa: nosotros sabíamos cómo arreglar el mundo. Es esta nota de arrogancia gratuita la que en parte explica la posterior respuesta reaccionaria; si la izquierda quiere recuperarse, le vendrá bien algo de modestia" (JUDT, 2011, p. 19. El subrayado es del autor).

${ }^{8}$ La variable tiempo en la construcción de la democracia ha sido resumida por Jon Elster como "la capacidad de los sistemas políticos para aprender del pasado y hacer planes a largo plazo" (1999, p.
} 
recientes, cabe incluir la advertencia que hiciera Juan Carlos Portantiero, en los primeros ańos de la transición, con respecto a los obstáculos de la difícil democratización latinoamericana: "debe importar tanto la cura como los síntomas afirma el sociólogo -, sobre todo cuando ellos se manifiestan en el interior de estructuras débiles como las sudamericanas con estados ineficientes y corruptos, sin un sistema de partidos representativos y con instituciones deslegitimadas, incapaces de disciplinar al poder económico y satisfacer la creciente demanda social” (PORTANTIERO, 2000; CHERESKI y POUSADELA, 2001; FERNÁNDEZ y LESGART, 2008) 9 .

Ahora bien, en la amplia literatura sobre la democracia ocupó siempre un lugar destacado la insistencia en la necesidad de contar con ciudadanos mínimamente comprometidos con la formación de una esfera pública democrática. Y ello como la condición sine qua non de estabilidad de las instituciones, aquellas que asegurarán en el futuro la realización de las tareas orientadas hacia la democratización de nuestras débiles democracias (GREPPI, 2012).

\section{Por una gobernanza democrática}

De acuerdo con el argumento aquí presentado, la esfera pública democrática se despliega en el terreno de la sociedad politica, que comprende todo el espacio de acción que se interpone entre la sociedad civil y el Estado democrático, espacio en el que se mueven actores individuales y colectivos, comprometidos con la defensa institucional del interés general. En otras palabras, se trata de actores que asumen la tarea de llevar a la práctica o conducir el despliegue del nuevo proyecto de orden democrático. Si partimos del hecho de que en el desarrollo de las prácticas políticas es preciso distinguir los tres principales espacios de la acción pública: sociedad civil, sociedad política y Estado, también debe destacarse su carácter indisociable en el

121). La cuestión de las temporalidades, en el origen de un conjunto de perplejidades y conflictos ha sido destacada por Pierre Rosanvallon, cuando advierte sobre las posiciones oscilantes de los diversos actores sociales: "entre una visión radicalmente instantaneísta de la democracia, presta en consecuencia a aferrarse a un poder ejecutivo que se autojustificaría en la fuerza de lo excepcional, y una justificación opuesta de su poder por parte de los expertos, considerados como los únicos aptos para "representar" los intereses sociales del largo plazo en nombre del conocimiento que pudieran llegar a poseer"(ROSANVALLON, 2003, p. 56). También Schedler y Santiso (1999).

9 Sobre esta cuestión resultan relevantes los dos textos seminales de Guillermo O'Donnell (1972 y 1982). Una perspectiva más amplia y abarcadora se encuentra en los textos corregidos y reunidos por O'Donnell (1997). 
funcionamiento del orden democrático. ¿En qué medida esta distinción es relevante para la cuestión de la democracia? Alain Touraine la retuvo en los preliminares de su concepción sociológica de la democracia:

La separación de la sociedad civil, la sociedad política y el Estado es una condición central para la formación de la democracia. Esta sólo existe si se reconocen las lógicas propias de la sociedad civil y del Estado, lógicas distintas y a menudo opuestas, y si existe, para manejar sus dificultosas relaciones, un sistema político autónomo frente a una como al otro. Lo que recuerda que la democracia no es un modo de existencia de la sociedad en su totalidad, sino verdaderamente de la sociedad politica y, al mismo tiempo, que el carácter democrático de la sociedad politica depende de las relaciones de ésta con la sociedad civil y con el Estado (TOURAINE, 1995, p. 68. El subrayado es mío) ${ }^{10}$.

Asimismo, en su concepción dinámica de la sociedad civil, John Keane ya había observado en la línea de los clásicos, particularmente de Alexis de Tocqueville y John Stuart Mill, hasta qué punto la separación entre Estado y sociedad civil constituye una característica permanente de un orden social y político plenamente democrático. Y ello de modo tal que,

\begin{abstract}
una sociedad civil democrática no puede nunca bastarse a sí misma, y necesita que el poder estatal defienda activamente su independencia. La democratización no es ni el enemigo declarado ni el amigo incondicional del poder estatal. Necesita que el Estado gobierne a la sociedad civil ni demasiado ni demasiado poco; al igual que un orden más democrático no puede construirse a través de un poder estatal, tampoco puede ser levantado sin el poder estatal (KEANE, 1992, p. 45. El subrayado es del autor) ${ }^{11}$.
\end{abstract}

En efecto, el proceso de formación de la sociedad política, como espacio relativamente autónomo, obedece a una relación de fuerzas que se desenvuelve dentro de una lógica que le es propia, es decir, posee su propio ritmo en el conjunto de acciones orientadas hacia la democratización del Estado: los poderes independientes

10 Sobre la interpenetración del Estado y la sociedad civil, debido a la expansión de las burocracias, que coincide históricamente con el agotamiento de las "formas autoritarias del poder", véase la tesis de Marcel Gauchet (1985, p. 284-288).

${ }^{11}$ El hecho de que la sociedad civil no sea necesariamente democrática es tratado por Thériault (1992) y Thuaut (1998). 
del Estado, aquellos que hacen vida en el espacio de la sociedad civil, bajo la forma de "intereses privados", van incorporándose a la sociedad política mediante la organización de los diversos intereses, constituyéndose en una "forma de acción colectiva" orientada hacia la defensa del "interés general" frente al Estado. En otras palabras, el espacio conquistado por el sistema político o sociedad política es "el lugar de la democracia" (TOURAINE, 1995, p. 70) o el terreno propicio para la construcción del orden democrático: las nuevas fuerzas sociales se suman a la acción de los partidos y sistemas de partidos en lo que se ha descrito, en la amplia literatura especializada, como proceso de "democratización del Estado"12.

Con la incorporación de las fuerzas organizadas de la sociedad civil a la lucha natural de los partidos se alcanza a establecer las "conexiones políticas" durables, aquellas que son requeridas para la democratización de la sociedad y del Estado, aunque este proceso no esté exento de provocar graves tensiones ${ }^{13}$. De aquí que lo que conocemos como gobernanza democrática presupone un cierto grado de politización del sector organizado y autónomo (formal o informal) de la sociedad civil. $\mathrm{Y}$ en la medida en que el orden democrático no se reduce a la competencia entre partidos, al gobierno de la mayoría e imperio de la ley, ese orden político, entendido como gobernanza efectiva, se extiende hacia los amplios espacios donde se mueven intereses vinculados con la búsqueda de la igualdad, la vigencia de libertades políticas y civiles y, en fin, la preservación de valores compartidos por la comunidad.

\footnotetext{
${ }^{12}$ Véase una primera observación sobre este proceso en Ramos Jiménez (2016). Afirmar que la crisis de los partidos condujo directamente a situaciones donde los medios de comunicación, los centros de investigación y unas cuantas ONG especializadas llegaron a desplazar a los partidos, particularmente en el terreno de la formación de la opinión pública, se ha vuelto un lugar común en los años recientes. Sin embargo, hoy en día una suerte de retorno de los partidos comienza a advertirse en el funcionamiento del orden democrático en un buen número de países. (DAALDER, 2007; RAMOS JIMÉNEZ, 2015).

${ }^{13}$ La expresión fue propuesta originalmente por Edmond Burke en su clásico Thoughts of the Cause of the Present Discontent (1770). De acuerdo con Burke "Las conexiones políticas son esencialmente necesarias para la plena realización de nuestro deber público, aunque pueden degenerar accidentalmente en facciones. Las comunidades políticas se componen de familias; las comunidades políticas libres se componen también de partidos y con la misma razón podemos afirmar que nuestros afectos naturales y lazos de sangre tienden inevitablemente a hacer de nosotros malos ciudadanos, que decir que los lazos de partido debilitan lo que nos une a nuestro país. Lo que sí es cierto es que los mejores patriotas en las comunidades politicas más grandes han defendido y fomentado siempre tales conexiones" (BLANCO VALDÉZ, 2001, p. 11. El subrayado es del autor; IGNAZI, 2000, p. 51-74).
} 
En la puesta en práctica de una genuina gobernanza democrática se adopta una dinámica específica que conduce el despliegue de la lógica de la representación (partidos y sistemas de partidos) en el espacio de la relación siempre conflictiva entre la sociedad política y el Estado. Solo entonces cabe hablar de Estado democrático:

Gracias a la representación - advierte Claude Lefort - el Estado no se encierra en sí mismo. El Estado no puede configurar el polo del poder total, aparecer como dotado de una permanencia y de una fuerza compactas, sino que el mismo está sometido a las demandas más diversas y no detenta, en última instancia, el poder de decisión. Este poder de decisión está asignado a un gobierno que es en sí mismo transitorio, un gobierno susceptible de ser reemplazado, un gobierno siempre dependiente de la adhesión del pueblo" (LEFORT, 1992, p. 142) ${ }^{14}$.

Y Tony Judt (2011, p. 20-21) para recordarnos que si bien es cierto que "el Estado va a permanecer con nosotros un tiempo previsible, haríamos bien en pensar qué tipo de Estado queremos".

En su conocida tesis sobre la developing democracy, Larry Diamond propuso distinguir a la sociedad civil, que incluye a los "ciudadanos que actúan colectivamente en la esfera pública, expresando sus intereses, pasiones, preferencias e ideas, para intercambiar información, a fin de alcanzar objetivos colectivos" (1999, p. 221. La traducción y el subrayado son míos), por una parte, de lo que, según él, debe conceptualizarse como la "sociedad en general", en la que se manifiestan los intereses personales, familiares y de las empresas y negocios privados, por otra.

En esta conceptualización, Diamond pone rápidamente de lado a los partidos políticos. Según este autor, se trata de formas de organización que solo "buscan encapsular a sus miembros en ambientes totalizantes", aislándolos de visiones y vínculos alternativos, inculcándoles rígidos sistemas de creencias ideológicos y filosóficos y, en fin, demandándoles total obediencia (DIAMOND, 1999, p. 221). La presente proposición trasciende esta concepción, al sugerir que el rol de los partidos y sistemas de partidos los convierte en los portadores naturales y específicos del ideal democrático, constituyéndose en los garantes efectivos del pluralismo democrático, por una parte y, en las formas de acción colectiva organizadas para conducir el proceso de democratización del Estado, por otra: sin la intervención de los partidos

\footnotetext{
${ }^{14}$ La tesis de la primacía o la revalorización de la sociedad política (partidos y sistemas de partidos) en las neodemocracias latinoamericanas la expuse por primera vez en Ramos Jiménez (1994).
} 
difícilmente las fuerzas organizadas de la sociedad civil podrían interpelar al Estado, controlar o regular la "arbitrariedad" del poder estatal, en fin, hacerlo más responsable (RAMOS JIMÉNEZ, 2015) ${ }^{15}$.

Asimismo, en la medida en que la construcción del orden político democrático presupone la intervención de los funcionarios de la sociedad política, su incorporación en los procesos de decisión solo se hará efectiva cuando los mismos han logrado intervenir decisivamente dentro del entramado institucional del Estado (gobierno, administración, parlamento, aparato judicial, poder local, fuerza armada, etc.). Porque, una sociedad es plenamente democrática desde el momento en que dispone de un aparato del Estado fuerte, limitado y responsable que, por lo mismo, ya cuenta con los medios y está en condiciones de preservar el orden democrático.

Debe quedar claro - observó Juan J. Linz en su conocido texto - "que los responsables del mantenimiento de un orden político democrático deberían recibir de los que creen en la legitimidad de tal orden el derecho a emplear la fuerza necesaria para parar a los contrarios dispuestos a usar la violencia para destruir o desequilibrar ese orden" (LINZ, 1987, p. 51). Diamond parece admitirlo cuando cita la lacónica afirmación de Juan Linz: "no state, no Rechtsstaat, no democracy" (DIAMOND, 1999; STEPAN, 2001). Afirmación que recoge una idea fundamental y crucial del pensamiento democrático desde hace mucho tiempo.

Sin embargo, el Estado democrático no podría hacerse cargo de tal responsabilidad si para ello no cuenta con cierto grado de legitimidad, sustentada esta última en niveles mínimos de eficacia. ¿Cómo un gobierno puede preservar su legitimidad, se pregunta Ezra Suleiman, si se priva él mismo de los medios para ser eficaz? (SULEIMAN, 2005). En sus conocidas observaciones sobre las "condiciones del orden democrático", Seymour M. Lipset destacó el hecho de que:

La legitimidad implica la capacidad del sistema para engendrar y mantener la creencia de que las instituciones políticas existentes son las más apropiadas para la sociedad. Hasta qué punto los sistemas politicos democráticos son legitimos, depende, en gran parte, de las formas en que se resolvieron los acontecimientos clave que dividieron históricamente a la sociedad. Mientras que la eficacia es fundamentalmente instrumental, la legitimidad es evaluativa. Los grupos consideran un sistema político como legitimo o ilegítimo según la

\footnotetext{
${ }^{15}$ Sobre el rol y funciones democratizadoras de los partidos véase Garretón (2004), Baquero (2000) y Milza (2006).
} 
manera en que sus valores concuerden con los propios (LIPSET, 1988, p. 67. El subrayado es mío) ${ }^{16}$.

Legitimidad y eficacia del orden democrático aparecen entonces identificadas con la intervención de aquellos grupos especializados en la búsqueda de racionalidad de las decisiones, asegurando con ello las condiciones mínimas de estabilidad del orden democrático. Tales grupos, ellos mismos en búsqueda constante de su propia legitimidad (reconocimiento y aceptación), serán los agentes encargados de alcanzar y mantener niveles aceptables de eficacia en el funcionamiento del Estado democrático. Legitimidad y eficiencia pública se presentan íntimamente vinculadas en la cuestión de la gobernanza democrática. Por ello, no debe extrañar el énfasis de Juan J. Linz cuando observa:

Los miembros de la sociedad, y hoy en día esto implica una gran colectividad, conceden poder político a la autoridad en un régimen para conseguir la satisfacción de sus intereses materiales e ideales. Nadie puede negar que el grupo dirigente es probable que trate de conseguir sus propios intereses materiales e ideales pero posiblemente no podria retener su legitimidad si los persiguiera exclusivamente o a un coste demasiado grande para un amplio sector de la sociedad (LINZ, 1987, p. 44. El subrayado es mío).

En la determinación de tales niveles radica la cuestión conflictiva y siempre problemática de las alternativas disponibles ante la creciente complejidad de las decisiones. Porque si bien es cierto el hecho de que la acción declinante de los partidos en las tareas de la democratización dejó sin sustento, en el período que se abre con el nuevo siglo, a todo proyecto de revisión o de reforma de Estados ineficientes, las recurrentes propuestas de "reforma del Estado" o de refundación de las burocracias públicas - el paso de la "burocracia como organización" al de la burocracia como "administración de lo público" -, que ya habían incorporado unos cuantos elementos tecnocráticos, terminaron encontrándose con una sociedad política reducida, fragmentada y débil, dejando al Estado sometido a la "arbitrariedad del poder”, afectando con ello el mínimo de legitimidad requerido para emprender en las necesarias tareas de la democratización.

\footnotetext{
${ }^{16}$ No deja de ser importante la observación de Larry Diamond (1999), para quien, el grado de eficacia de una democracia no se relaciona tan fuertemente con el apoyo de los ciudadanos que, en la defensa de sus intereses, privilegian factores políticos como las libertades públicas.
} 
Asimismo, en momentos en que asistimos a un repliegue de las ideologías y utopías, aquellas que debían asignarle contenido y consistencia exterior al orden político de corte democrático, este último se encontró con la pesada carga de reunir en su interior los recursos necesarios para su justificación. "La legitimidad - nos recuerda Pierre Rosanvallon - es como la confianza entre individuos, una <<institución invisible>> (...) su variante democrática tiene la función más exigente, la de tejer los vínculos constructivos entre el poder y la sociedad. Contribuye a dar cuerpo a aquello que constituye la esencia de la democracia: la apropiación social de los podere" (2008, p. 21. La traducción es mía).

En efecto, el funcionamiento de la burocracia en condiciones de democratización tiende a identificar a la misma con la sociedad política, tiende asimismo a establecer líneas de comportamiento autónomas o "independientes" frente al Estado. El aparato burocrático está entonces en capacidad de influir en la dirección y control de la acción estatal, tanto en la determinación de los objetivos como en la administración de los recursos. Solo entonces los ciudadanos pueden y deben pedir cuentas. La presencia de una genuina burocracia weberiana (neutralidad, impersonalidad, profesionalización y especialización) contribuye decisivamente al funcionamiento democrático del Estado. Y en tal sentido, hablar de burocracia ineficiente es una contradicción en los términos.

La construcción de una gobernanza democrática, asociada con el logro de niveles de eficiencia o eficacia, presupone también la presencia de formas de acción colectiva, imprescindibles en el contexto de la democratización. Los actores comprometidos con la gobernanza democrática se mueven en tres principales espacios de la acción pública, como actividad previa a la toma de decisiones. En primer lugar, en el espacio de la "clase política" o de las élites, que cuentan con el poder e influencia sobre lo que se hace y se deja de hacer: líderes gubernamentales, líderes de partidos y otras organizaciones relevantes (Iglesias, universidades, sindicatos y gremios profesionales), formadores de opinión en los medios, activistas políticos, jefes de empresas básicas. Este espacio de las élites es el espacio privilegiado para la competición y negociación democráticas ${ }^{17}$. Es el espacio natural, más que simbólico,

\footnotetext{
${ }^{17}$ En su investigación sobre el Estado de partidos, Klaus von Beyme propone distinguir "clase política" de "élite", en la medida en que, "el término de élite está más referido a la acción política que el concepto de clase política (...) La especificación <<élite política > es más limitada que el concepto de clase política" (1995, p. 29-30). Aquí hacemos referencia a la "clase política" como la estructura social
} 
del gobierno representativo y, por lo mismo, espacio donde se juega el destino de la democracia: las luchas por la promoción y defensa del orden democrático son primero luchas inter-élites. Su despliegue comienza en el espacio de las élites.

En un espacio intermedio se mueven los miembros de los partidos políticos, movimientos sociales, grupos de opinión y de interés, con alta capacidad de movilización y con intervenciones cruciales en la toma de decisiones relevantes. Conjuntamente con las élites, son los actores imprescindibles en la construcción del orden democrático. En fin, el tercer espacio corresponde a la masa de gobernados, que reúne a la mayoría de ciudadanos, que puede activarse en situaciones de crisis o de inestabilidad política.

En la construcción del orden democrático, la presencia de una genuina burocracia weberiana, atenta a la demanda ciudadana de legitimidad y eficacia; de una tecnocracia, que aporte a la decisión capacidad y "conocimiento experto" - cada vez más necesario para el funcionamiento de la democracia -, que logre superar su renuencia a incorporarse políticamente a las tareas de construcción y mantenimiento del orden propuesto y, en fin, de una meritocracia experimentada, consciente de su responsabilidad y sin prejuicios, representan en nuestros días, tanto como los partidos, los agentes comprometidos y garantes de las condiciones mínimas de legitimidad y eficiencia, requeridas para la estabilidad y funcionamiento del orden democrático. Porque en la medida en que los regímenes ilegítimos e ineficientes no son, en modo alguno, democráticos, son por definición gobiernos inestables, que siempre se sentirán tentados a utilizar la fuerza para mantener sus posiciones de poder.

\section{Contra la simplificación populista}

De acuerdo con una idea un tanto extendida, las dinámicas populistas en nuestros países no representan en sí mismas movimientos antidemocráticos. Por el contrario, tanto en nuestros países latinoamericanos como en el caso de la Europa occidental, buena parte de la retórica populista promueve una "mejor democracia", siempre con el recurso a la denuncia de "las perversiones de la democracia existente". En este sentido, Yves Mény e Yves Surel consideraron a la oferta populista como una manifestación inequívoca de "corrupción ideológica de la democracia", puesto que de acuerdo con estos autores:

a la que pertenecen todos los que participan en la toma de decisiones vinculantes para la sociedad en su conjunto. 
Lejos de preconizar otra forma de régimen (distinta a la democracia), los populistas se comprometen más a menudo con una suerte de incremento de las promesas democráticas utilizando las ambigüedades y la polisemia que caracterizan al término democracia. Proponen con ello su $<<$ regeneración $>>$, limpiándola de todas sus escorias, retornando a los $<<$ verdaderos $>>$ principios $y$ valores (MÉNY e SUREL, 2000, p. 32. La traducción y el paréntesis son míos) ${ }^{18}$.

Asimismo, en su reflexión sobre la política democrática en lo que él denomina "la era de la desconfianza", Pierre Rosanvallon llegó a identificar al populismo como una "patología de la democracia electoral-representativa”, desde el momento en que los líderes populistas contemporáneos:



El surgimiento de líderes populistas en situaciones críticas es la norma en el desarrollo de las precarias neodemocracias latinoamericanas. Pero ello no sería tan significativo si no fuera por el hecho de que el fenómeno siempre estuvo acompańado de una gran simplificación, con la cual, unos cuantos demagogos recién llegados a la política se abrieron camino explotando la ira, frustración y resentimiento de la población. Sin otro recurso que el de las promesas atractivas y sobredimensionadas, tales líderes han venido identificándose como los legítimos portadores de fórmulas de movilización popular que, por lo general, consisten en lo que Moisés Naím ha

\footnotetext{
${ }^{18}$ Este tipo de corrupción lo hemos identificado en el caso de la Venezuela de Chávez (RAMOS JIMÉNEZ, 2002, 2006 e 2009). También ha sido tratado en los trabajos de Hermet (2001); Rioux (2007); Taguieff (2007). Aportes relevantes para la discusión bien informada se encuentran en De la Torre y Peruzzotti (2008) y Malamud (2010).

19 Tómese con las debidas reservas el libro oportunista de Ernesto Laclau (2005), abundante en retórica radical, utilizado para la justificación de los regímenes neopopulistas (2005). En la línea de Laclau véase Diana Raby (2008). (RAMOS JIMÉNEZ, 2006a, 2008a y 2008b).
} 
denominado "terribles simplificaciones inmunes a las lecciones de la experiencia e incluso a los datos y las pruebas científicas" $(2013 \text {, p. } 345)^{20}$.

Como respuesta a las situaciones de crisis recurrentes en nuestros países, por una parte, y a la peligrosa desmovilización antipolítica, por otra, las simplificaciones populistas no han sido otra cosa que la respuesta expedita de líderes mesiánicos, individuos carismáticos, portadores de soluciones fáciles y grandilocuentes, para los problemas más acuciantes de ciudadanos desencantados de la democratización. Tales líderes, campeones de la duplicidad y hábiles prestidigitadores, que llegan a convertirse en exitosos vendedores de ilusiones en el aburrido mercado electoral, portadores de promesas cada vez más vacías de contenido, no se detienen a la hora de encontrar la oportunidad de desplazar a los políticos de partido de sus posiciones de poder.

En los ańos recientes se ha destacado con insistencia el hecho de que los errores y dificultades de las fuerzas empeñadas en la construcción del orden democrático, sea en el seno del gobierno, o bien en el de la oposición democrática, están en el origen de sentimientos y actitudes negativas en la población (RAMOS JIMÉNEZ, 2011a, 2011b y 2006c) ${ }^{21}$. Y en la medida en que estas últimas se van extendiendo, llegan hasta minar la confianza necesaria para el funcionamiento y consolidación de la sociedad política: partidos políticos y movimientos o grupos de interés comprometidos con la democracia ven limitados de este modo sus esfuerzos encaminados a contrarrestar las arremetidas de los simplificadores populistas que, mediante promesas atractivas y engañosas, se presentan y logran hacerse aceptar como los constructores de la ansiada alternativa, anunciando de paso la llegada de "tiempos mejores": las "democracias electorales" en formación van siendo desplazadas por formas alternativas plebiscitarias (RAMOS JIMÉNEZ, 2006c y 2016).

La desmitificación de la simplificación populista debe constituirse en una tarea urgente para el pensamiento democrático latinoamericano. Tal vez de ello dependa buena parte de los esfuerzos requeridos para el establecimiento de las bases

\footnotetext{
${ }^{20}$ Naím sostiene que frente a los simplificadores populistas, los demócratas necesitan algo que en el pasado reciente se ha revelado muy difícil: "Una mayor disposición de las sociedades democráticas a dar más poder a quienes nos gobiernan. $\mathrm{Y}$ eso es imposible mientras no confiemos más en ellos. Lo cual es, por supuesto, más difícil. Pero también indispensable" (2013, p. 345).

${ }^{21}$ En su investigación sobre el rol de los "ciudadanos comunes y corrientes" en la quiebra de las democracias latinoamericanas, Nancy Bermeo (2003) ha destacado el hecho de que en la reversión de los gobiernos democráticos, las élites son las primeras y más activas en la agitación que precede a la participación (TILLY, 2010; TARROW, 2012).
} 
de la construcción y preservación de un genuino orden democrático. La superación de una tal simplificación pasa por el fortalecimiento de la sociedad política. Y en este empeńo, un mayor protagonismo de los partidos no debe verse como una intrusión indebida. Hace cierto tiempo, Thomas Carothers (2006) asomó la tesis, un tanto controversial, según la cual la ayuda significativa a los partidos políticos (entrenamiento de los líderes, asesoramiento en las campańas electorales y en la determinación de las reformas que se precisan), debe anteponerse a la ayuda financiera directa a los Estados. Y en la medida en que el fenómeno populista siempre ha cobrado fuerza en las situaciones de declive profundo de las fuerzas sociales organizadas en partidos, el fortalecimiento de estos últimos debe considerarse como la tarea crucial en las transiciones y consolidaciones del orden democrático. En otras palabras, la buena salud de los partidos políticos representa una de las condiciones clave para el buen funcionamiento del orden democrático.

Alfredo Ramos Jiménez é Doutor em Ciência Política, pela Universidade Paris Panthéon-Sorbonne. É Professor Emérito da Faculdade de Ciências Jurídicas e Politicas da Universidade dos Andes e Diretor do Centro de Investigações de Politica Comparada. E-mail: alfredoramosj@hotmail.com.

\section{Referências}

ANDERSON, Lisa (org.). Transitions to Democracy. New York: Columbia University Press, 1999.

BAQUERO, Marcello. A vulnerabilidade dos partidos politicos e a crise da democracia na America Latina. Porto Alegre: Editora da UFRGS, 2001.

BERMEO, Nancy. Ordinary People in Extraordinary Times: The Citizenry and the Breackdown of Democracy. Princeton: Princeton University Press, 2003.

BEYME, Klaus von. La clase politica en el Estado de partidos, Madrid: Alianza, 1995.

BLANCO VALDEZ, Roberto L. Las conexiones políticas, Madrid: Alianza, 2001.

BOBBIO, Norberto. El futuro de la democracia. México: Fondo de Cultura Económica, 1986.

BURKE, Edmond. Thoughts of the Cause of the Present Discontent. 1770.

CAROTHERS, Thomas. Confronting the Weakest Link. Aiding Political Parties in New democracies. Washington: Carnegie Endowment for International Peace. 2006.

CAVAROZZI, Marcelo; ABAL MEDINA, Juan M. (org.). El asedio a la política. Los partidos latinoamericanos en la era neoliberal. Rosario: Homo Sapiens. 2002. 
COUFFIGNAL, Georges (org.). Amérique latine. Les surprises de la démocratie. Paris: IHEAL/La Documentation Française, 2007.

CRICK, Bernard. En defensa de la politica. Barcelona; Tusquets Editores, 2001. (Ed. original 1962).

CHERESKI, Isidoro; POUSADELA, Inés (org.). Politica e Instituciones en las nuevas democracias latinoamericanas. Buenos Aires: Paidós. 2001.

DAALDER, Hans. ¿Partidos negados, obviados o redundantes? Una crítica. In: MONTERO, José Ramón; GUNTHER, Richard; LINZ, Juan J. (Eds.). Partidos politicos. Viejos conceptos y nuevos retos. Madrid: Trotta, 2007, p. 49-69.

DAHL, Robert A. La democracia. Barcelona: Ariel-Quintaesencia, 2012).

DE LA TORRE, Carlos; PERUZZOTTI, Enrique (org.). El retorno del pueblo. Populismo y nuevas democracias en América Latina. Quito: FLACSO/Ministerio de Cultura, 2008.

DIAMOND, Larry. Developing Democracy. Toward Consolidation. Baltimore: The John Hopkins University Press, 1999.

DIAMOND, Larry; PLATTNER, Marc Plattner (org.). El resurgimiento global de la democracia, México: UNAM/Instituto de Investigaciones Sociales, 1996.

DUNN, John. La agonía del pensamiento politico occidental. Madrid: Universidad de Cambridge, 1996.

ELSTER, Jon; SLAGSTAD, Rune. Las consecuencias de la elección constitucional: Reflexiones sobre Tocqueville. In: ELSTER, Jon; SLAGSTAD (org.). Constitucionalismo y democracia. México: Fondo de Cultura Económica, 1999, p. 111-145.

FERNÁNDEZ, Arturo; LESGART, Cecilia (org.). La democracia en América Latina. Partidos políticos y movimientos sociales. Rosario: Homo Sapiens, 2008.

GARRETÓN, Manuel Antonio. La indispensable y problemática relación entre partidos y democracia. In: PNUD (org.). La democracia en América Latina. Hacia una democracia de ciudadanas y ciudadanos. Contribuciones para el debate. Buenos Aires: Aguilar, 2004. p. 72-97.

GAUCHET, Marcel. Le désenchantement du monde Paris: Gallimard, 1985.

GEDDES, Bárbara. What Causes Democratization. In: GOODIN, Robert F (org.). The Oxford Handbook of Political Science. Oxford: Oxford University Press, 2009, p. 593-615.

GREPPI, Andrea. La democracia y su contrario. Representación, separación de poderes y opinión pública. Madrid: Trotta, 2012.

HAGOPIAN, Frances; MAINWARING, Scott (org.) The Third Wave of The Democratization in Latin America. Advances and Setbacks. Cambridge: Cambridge University Press. 2005.

HELLINGER, Daniel C. Comparative Politics of Latin America. Democracy at Last. New York: Routledge, 2011.

HERMET, Guy. Démocratie et autoritarisme. Paris: Les Éditions du Cerf, 2012. Les populismes dans le monde. Une histoire sociologique XIX-XXe. Siècle Paris: Fayard, 2001. En las fronteras de la democracia. México, Fondo de Cultura Económica, 1989.

IGNAZI, Piero. Le povoir du parti politique. In: DREYFUS, Françoise (org.). Nouveaux partis, nouveaux enjeux. Paris: Publications de la Sorbonne, 2000, p. 51-74.

JUDT, Tony. Algo va mal. Caracas: Taurus, 2011.

KEANE, John. Democracia y sociedad civil. Madrid: Alianza, 1992.

LACLAU, Ernesto. La razón populista. Buenos Aires: Fondo de Cultura Económica, 2005. 
LECHNER, Norbert. La conflictiva y nunca acabada construcción del orden deseado. In: LECHNER, Norbert. Obras II. ¿Qué significa hacer politica? México: FLACSO/Fondo de Cultura Económica. 2013, p. 267-421.

LEFORT, Claude. La representación no agota la democracia. In: DOS SANTOS, Mario (org.). ¿Qué queda de la representación politica?, Caracas: Nueva Sociedad-CLACSO, 1992, p. 139-145.

LEVINE, Daniel; MOLINA, José Enrique (org.). The Quality of Democracy in Latin America. Boulder, Colorado: Lynne Rienner, 2011.

LINZ, Juan J. Democracy Today: An Agenda for Students of Democracy. Scandinavian Political Studies, v. 20, n. 2, 1997.

. La quiebra de las democracias. Madrid: Alianza, 1987.

LIPSET, Seymour Martin. El hombre politico. Las bases sociales de la política. Buenos Aires: TecnosREI, 1988.

MAINWARING, Scott; PÉREZ-LIÑÁN, Aníbal. Democracies and Dictatorship in Latin America. Cambridge: Cambridge University Press. 2014.

MAINWARING, Scott; BEJARANO, Ana María; PIZARRO, Eduardo (org.). La crisis de la representación democrática en los países andinos. Bogotá: Norma. 2008.

MALAMUD, Carlos. Populismos latinoamericanos. Los tópicos de ayer, de hoy y de siempre. Madrid: Ediciones Nobel, 2010.

MAHONEY, James. Knowledge Accumulation in Comparative Historical Research. The Case of Democracy and Authoritarianism. In: MAHONEY, James; RUESCHMEYER, Dietrich (org.). Comparative Historical Analysis in the Social Sciences. Cambridge: Cambridge University Press, 2003), p. 131-174.

MAYORGA, René Antonio. Antipolitica y neopopulismo. La Paz: CEBEM, 1995.

MAZZUCA, Sebastián. Reconceptualizing Democratization: Access to Power Versus Exercise of Power. In: MUNCK, Gerardo L. (org.). Regimes and Democracy in Latin America. Theories and Methods. Oxford: Oxford University Press, 2007. p. 39-49.

MÉNY, Yves; SUREL, Yves. Par le peuple, pour le peuple. Le populisme et les démocraties. Paris, Fayard, 2000.

MIRZA, Christian. Movimientos sociales y sistemas politicos en América Latina. La construcción de nuevas democracias, Buenos Aires: CLACSO, 2006.

MORLINO, Leonardo. Changes for Democracy. Actors, Structures, Processes. Oxford: Oxford University Press. 2012

- ¿Cómo analizar las calidades democráticas? Revista Latinoamericana de Politica Comparada, Quito, n. 10, p. 13-36. 2015.

. Democracias y democratizaciones. México: Centro de Estudios de Política Comparada. 2005.

MULGAN, Geolf. Politics in an Antipolitical Age, Londres: Polity Press, 1994.

MUNCK, Gerardo L. The study of Politics and Democracy: Touchstones of a Research Agenda. In: MUNCK, Gerardo L. (org.). Regimes and Democracy in Latin America: Theories and Methods. Oxford: Oxford University Press, 2007, p. 25-37.

NAÍM, Moisés. El fin del poder. Empresas que se hunden, militares derrotados, papas que renuncian y gobiernos impotentes. Cómo el poder ya no es lo que era. Madrid: Random House Mondadori, 2013. 
NEWTON, Kenneth; NORRIS, Pippa. Confidence in Public Institutions: Faith, Culture, or Performance?. In: PHARR, Susan J.; PUTNAM, Robert D. (org.) Dissafected Democracies. What's Troubling the Trilateral Countries?. Princeton: Princeton University Press, 2000, p. 52-73.

NUN, José. Democracia ¿Gobierno del pueblo o gobierno de los políticos? Buenos Aires: Fondo de Cultura Económica, 2000, p. 139-140.

O'DONNELL, Guillermo. Contrapuntos. Ensayos escogidos sobre autoritarismo y democratización. Buenos Aires: Paidós, 1997. 1966-1973. El estado burocrático-autoritario. Buenos Aires: Editorial de Belgrano, 1982. Modernización y autoritarismo, Buenos Aires: Paidós, 1972.

PORTANTIERO, Juan Carlos. Revisando el camino. Las apuestas de la democracia en Sudamérica. In: LÓPEZ, Ernesto; MAINWARING, Scott (org.). Democracia: Discusiones y nuevas aproximaciones. Buenos Aires: Universidad Nacional de Quilmes, 2000, p. 331-332.

PRZEWORSKI, Adam. Qué esperar de la democracia. Limites y posibilidades del autogobierno. Buenos Aires: Siglo veintiuno editores. 2010.

. Minimalist Conception of Democracy: A Defense. In: DAHL, Robert A.; SHAPIRO, Ian; CHEIBUB, José Antonio (org.). The Democracy Source Book. Cambridge: The MIT Press, 2003, p. $12-17$

RABY, Diana. Democracia y revolución: América Latina y el socialismo hoy. Caracas: Monte Ávila Editores, 2008.

RAMOS JIMÉNEZ, Alfredo. Las formas modernas de la politica. Estudio sobre la democratización de América Latina. Mérida: Centro de Investigaciones de Política Comparada-Universidad de Los Andes. Tercera edición revisada y ampliada, 2016.

. Los partidos políticos latinoamericanos. Una segunda mirada. Mérida: Centro de Investigaciones de Política Comparada, 2015.

. El liderazgo del "nuevo comienzo". Notas sobre el fenómeno Chávez. In: RAMOS JIMÉNEZ, Alfredo (org.). La revolución bolivariana. El pasado de una ilusión. Caracas: La Hoja del Norte, 2011a., p. 97-121,

. La <<revolución >> que no fue. Desgobierno y autoritarismo en la Venezuela de Chávez, Estudios Políticos, Medellín, no 38, Enero- Junio de 2011b, p. 69-91.

El experimento bolivariano. Liderazgo, partidos y elecciones. Mérida: Centro de Investigaciones de Política Comparada, 2008a.

Del proyecto de <<socialismo del siglo XXI >> al populismo realmente existente. Politeia. Revista de Ciencias Politicas, Caracas. n. 40, p. 175-197. 2008b.

Populismo del siglo XXI, Comunicación, Caracas, n. 135, p. 109-110, 2006 a.

. Democracia y liderazgo político. Una relación conflictiva en la experiencia venezolana. In: CADENAS, José María (Ed.). Debate sobre la democracia en América. Caracas: CEA/Universidad Central de Venezuela, 2006b, p. 13-35.

- De la democracia electoral a la democracia plebiscitaria. Elecciones y referendos en la Venezuela de Chávez. Revista Venezolana de Ciencia Política, Mérida, n. 29, p.7-37. 2006c.

. Sobrevivir sin gobernar. El caso de la Venezuela de Chávez. Nueva Sociedad, Caracas, n. 193, p. 17-27, Septiembre-Octubre 2004. 
. Los límites del liderazgo plebiscitario. El fenómeno Chávez en perspectiva comparada. In: RAMOS JIMÉNEZ, Alfredo (org.). La transición venezolana. Aproximación al fenómeno Chávez. Mérida: Centro de Investigaciones de Política Comparada, 2002, p.15-46.

. Viejo y nuevo, Partidos y sistemas de partidos en las democracias andinas, Nueva Sociedad, Caracas, n. 173, p. 65-76, 2001.

. Sobre la revalorización de la sociedad política en la democracia. In: LANZ, Rigoberto (org.). El malestar de la política. Mérida: Universidad de los Andes, 1994, p. 78-98.

RIOUX, Jean-Pierre. Le peuple à l'inconditionnel. In: RIOUX, Jean-Pierre (org.). Les populismes. Paris: Perrin, 2007, p. 7-16.

RIVAS LEONE, José Antonio. En los bordes de la democracia. La militarización de la política venezolana. Mérida: Centro de Investigaciones de Política Comparada. Universidad de Los Andes, 2010.

ROSANVALLON, Pierre. El buen gobierno. Buenos Aires: Manantial, 2015. . La légitimité démocratique. Imparcialité, réflexivité, proximité. Paris: Seuil, 2008. - La contre-démocratie. La politique à l'âge de la défiance. Paris: Seuil, 2006.

2003. . Por una historia conceptual de lo político. Buenos Aires: Fondo de Cultura Económica,

ROUQUIÉ, Alain. A l'ombre des dictatures. La démocratie en Amérique latine. Paris: Albin Michel. 2010.

SARTORI, Giovanni. Teoría de la democracia. 1. El debate contemporáneo. Madrid: Alianza, 1988.

SCHEDLER, Andreas; SANTISO, Javier (org.), Tiempo y democracia. Caracas: Nueva Sociedad. 1999.

SCHUMPETER, Joseph. Capitalismo, socialismo y democracia. Barcelona: Orbis. 1983. Edición original, 1942.

SMITH, William C. (org.). Latin American Democratic Transformations. Institutions, Actors and Processes. Miami: Wiley-Blackwell. 2009.

STEPAN, Alfred. Arguing Comparative Politics. Oxford: Oxford University Press. 2001.

SULEIMAN, Ezra. Le démantelement de l'État democratique. Paris: Seuil. 2005.

TAGUIEFF, Pierre-André. L'illusion populiste. Essai sur les démagogies de l'âge démocratique. Paris: Flammarion. 2007.

TARROW, Sidney G. El poder en movimiento. Los movimientos sociales, la acción colectiva y la politica. Madrid: Alianza. Tercera edición 2012.

THÉRIAULT, J.-Yvon. La société civile est-elle démocratique?, In: BOISMENU, Gérard (org.). Les formes modernes de la démocratie. Montréal-Paris: PUM-L'Harmattan. 1992, p. 67-79.

THUAUT, Jean-François. La fin de la représentation et les formes contemporaines de la démocratie. Paris: Éditions Nota Bene. 1998.

TILLY, Charles. Confianza y gobierno. Buenos Aires: Amorrortu. 2010.

TOURAINE, Alain. ¿Qué es la democracia? Buenos Aires: Fondo de Cultura Económica. 1995.

VANDEN, Harry E.; PREVOST, Gary. Politics of Latin America. The Power Game. Oxford: Oxford University Press. 2002.

WHITEHEAD, Laurence. Democratización. Teoría y experiencia. México: Fondo de Cultura Económica. 2011. 
152 | Alfredo Ramos Jiménez

Texto recebido em 07 de dezembro de 2016. Aprovado em 12 de dezembro de 2016. 